\title{
Is the future already here? The impact of climate change on the distribution of the eastern coral snake (Micrurus fulvius)
}

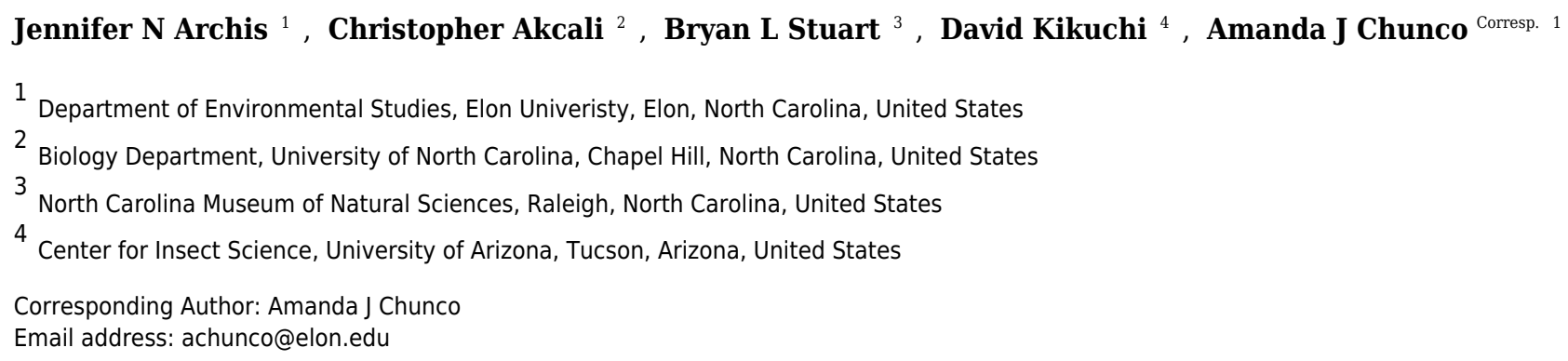

Anthropogenic climate change is a significant global driver of species distribution change. Although many species have undergone range expansion at their poleward limits, data on several taxonomic groups are still lacking. A common method for studying range shifts is using species distribution models to evaluate current, and predict future, distributions. Notably, many sources of 'current' climate data used in species distribution modeling use the years 1950-2000 to calculate climatic averages. However, this does not account for recent (post 2000) climate change. This study examines the influence of climate change on the eastern coral snake (Micrurus fulvius). Specifically, we: (1) identified the current range and suitable environment of $M$. fulvius in the Southeastern United States, (2) investigated the potential impacts of climate change on the distribution of $M$. fulvius, and (3) evaluated the utility of future models in predicting recent (2001-2015) records. We used the species distribution modeling program Maxent and compared both current (19502000 ) and future (2050) climate conditions. Future climate models showed a shift in the distribution of suitable habitat across a significant portion of the range; however, results also suggest that much of the Southeastern United States will be outside the range of current conditions, suggesting that there may be no-analog environments in the future. Most strikingly, future models were more effective than the current models at predicting recent records, suggesting that range shifts may already be occurring. These results have implications for both M. fulvius and its Batesian mimics. More broadly, we recommend future Maxent studies consider using future climate data along with current data to better estimate the current distribution. 
1

2 Is the future already here? The impact of climate change on the distribution of the eastern coral snake (Micrurus fulvius)

4

5 Jennifer N. Archis ${ }^{1}$, Christopher Akcali ${ }^{2}$, Bryan L. Stuart ${ }^{3}$, David Kikuchi ${ }^{4}$, Amanda J. Chunco ${ }^{1}$ Running Title: Climate data, Maxent, and coral snakes

7

81 Department of Environmental Studies, Elon University, Elon, North Carolina, USA

92 Biology Department, University of North Carolina at Chapel Hill, Chapel Hill, North Carolina, 10 USA

113 North Carolina Museum of Natural Sciences, Raleigh, North Carolina, USA

124 Center for Insect Science, University of Arizona, Tucson, Arizona, USA

14 Corresponding author: Amanda Chunco, achunco@elon.edu, (336) 278-6275 


\section{Abstract}

Anthropogenic climate change is a significant global driver of species distribution change. Although many species have undergone range expansion at their poleward limits, data on several taxonomic groups are still lacking. A common method for studying range shifts is using species distribution models to evaluate current, and predict future, distributions. Notably, many sources of 'current' climate data used in species distribution modeling use the years 1950-2000 to calculate climatic averages. However, this does not account for recent (post 2000) climate change. This study examines the influence of climate change on the eastern coral snake (Micrurus fulvius). Specifically, we: (1) identified the current range and suitable environment of $M$. fulvius in the Southeastern United States, (2) investigated the potential impacts of climate change on the distribution of $M$. fulvius, and (3) evaluated the utility of future models in predicting recent (2001-2015) records. We used the species distribution modeling program Maxent and compared both current (1950-2000) and future (2050) climate conditions. Future climate models showed a shift in the distribution of suitable habitat across a significant portion of the range; however, results also suggest that much of the Southeastern United States will be outside the range of current conditions, suggesting that there may be no-analog environments in the future. Most strikingly, future models were more effective than the current models at predicting recent records, suggesting that range shifts may already be occurring. These results have implications for both M. fulvius and its Batesian mimics. More broadly, we recommend future Maxent studies consider using future climate data along with current data to better estimate the current distribution. 


\section{INTRODUCTION}

Climate change is dramatically altering the distribution of species across the globe (Parmesan 2006; Chen et al., 2011). Climate change has been hypothesized to drive range shifts at poleward range limits, especially for warm-adapted species (Parmesan 2006). Hughes (2000) notes that a change of 3 degrees Celsius can result in poleward isotherm shifts of 300-400 km in temperate zones; the ranges of species are expected to expand in response. Indeed, in a review of range shifts in 434 species of varied taxa including birds, butterflies, and alpine herbs, $80 \%$ had moved in the direction predicted by climate change (Parmesan \& Yohe 2003). The cascading effects of range shifts are manifold and include: decoupling of intricate predator-prey interactions and multitrophic effects (Gilman et al. 2010), increased invasion (Hellmann et al. 2008) and infection (Pounds et al. 2006), increased intraspecific competition (Huey et al. 2009), and potential competitive exclusion in extreme cases (Gilman et al. 2010; Tylianakis et al. 2008; Chapin III et al. 2000).

The ranges of ectothermic taxa may be especially sensitive to the effects of climate change. In ectotherms, body temperature is either closely linked to environmental conditions, i.e., poikilothemy, or is regulated behaviorally (Huey 1982). Thus, ectotherms must rely on particular climate conditions to maintain proper metabolic function (Currie 2001; Hansen et al. 2001) and to optimize reproductive physiology (Girons 1982). Both mean temperature and precipitation, as well as variation in temperature and precipitation, have been shown to influence performance in ectotherms (Clusella-Trullas et al. 2011). Because of this strong reliance on temperature and the reduced energy costs for thermoregulation predicted to occur as a result of climate change in many temperate areas, 
60 it has been hypothesized that many reptile species will show an increase in range size 61 (Currie 2001; Hansen et al. 2001). Despite the importance of environmental conditions on physiological performance in reptiles, relatively few studies have assessed the impact of climate change on reptile species. For example, two major reviews on distributional shifts (Parmesan \& Yohe 2003; Parmesan 2006) included only two reptile species, both lizards. An additional metaanalysis (Chen et al., 2011) only included a single paper on reptiles and amphibians, and that study was geographically restricted to Madagascar. Thus, snakes provide a unique opportunity to examine the generality of patterns in range shifts for ectotherms. Although coral snakes are well-known for their striking coloration (Fig. 1) and potent venom, relatively little is known about the natural history of this species (Steen et al., 2015; Jackson \& Franz 1981). M. fulvius has historically ranged throughout the Southeastern United States from the southern tip of Florida to the Sandhills of North Carolina (Fig. 2). At a coarse scale, Micrurus fulvius inhabits sandy flatwoods and maritime forests (Beane et al. 2010), and one recent survey suggest a microhabitat preference for sandy soils and scrub/shrub habitat (Steen et al, 2015). Their diet primarily consists of other snakes and lizards (Beane et al. 2010). Although the International Union for the Conservation of Nature (IUCN) listed M. fulvius as "Least Concern" in 2007 based on its total global population size (Hammerson 2007), it is of significant conservation concern at the local level throughout most of its range; it is listed as Endangered in North Carolina (North Carolina Wildlife Resources Commission 2014), Imperiled in South Carolina (South Carolina Department of 
82 Natural Resources 2014), and of Highest Conservation Concern in Alabama (Alabama

83 Department of Conservation and Natural Resources 2017). The fate of these populations at

84 the edges of its range depends on how its range shifts in response to climate change.

predicting range shifts resulting from anthropogenic climate change. This approach

integrates species occurrence data with environmental variables to predict suitable

environments (Pearson \& Dawson 2003; Graham et al. 2004; Fitzpatrick et al. 2008).

Species Distribution Models have also been used to predict future range shifts due to

climate change by creating a SDM using current climate conditions and projecting that

model onto future predicted climate conditions (Thomas et al. 2004; Araújo et al. 2005;

92 Guisan \& Thuiller 2005; Hole et al. 2011).

One of the most common datasets used in SDMs is WorldClim, which provides

interpolated bioclimatic layers based on weather station data collected between 1950-

2000 (Hijamns et al. 2005). This dataset has been cited more than 10,100 times per Google

Scholar as of June 1,2017 . Yet, the magnitude of climate change that has taken place since 2000 (Karl et al. 2015) may have already rendered these 'current' climate conditions less accurate at predicting species distributions than 'future' climate predictions. by: (1) identifying the current range and suitable environments of $M$. fulvius in the Southeastern United States, (2) predicting future shifts in the range of $M$. fulvius under different climate change scenarios, and (3) comparing the effectiveness of both current and 
104

105

106

107

108

109

110

111

112

113

114

115

116

117

118

119

120

121

122

123

124

125

126

\section{METHODS}

\subsection{Species Distribution Modeling - Current Climate}

The ecological niche program Maxent version 3.3.3k (Phillips et al. 2004) was used to create a correlative species distribution model, executed through the Java Applet. Maxent uses environmental data from locations where the species of interest has been observed to create a map of habitat suitability across the area of interest. Maxent was chosen over competing modeling approaches because it has been well validated for use with presenceonly data and is capable of dealing with complex interactions between response and predictor variables (Elith et al. 2006) while remaining robust to small sample sizes (Wisz et al. 2008). Presence-only methods, which do not require costly and difficult-to-collect absence data (Gu \& Swihart 2004), can be used to model the same environmental relationships as presence-absence methods provided that biases are accounted for (Elith et al. 2011). This is especially useful for M. fulvius because, as is the case for most snake species, they are difficult to detect due to their limited active periods and cryptic behavior (Christoffel \& Lepcyzk 2012; Guimaraes et al. 2014). In addition, snake species are often patchily distributed and have low population sizes (Segura et al. 2007) making it difficult to obtain robust absence data.

Locality information was provided by herpetology collections from museums throughout the United States. These data were retrieved from multiple sources: the HerpNet2Portal (www.HerpNet2.org, accessed 2012-05-30; note that HerpNet has been folded into VertNet and specimen information is now available through http://portal.vertnet.org/search); the Global Biodiversity Information Facility (GBIF) (www.gbif.org, accessed 2013-06-26); iDigBio (www.idigbio.org, accessed 2016-05-23); 
127 and some locality points were provided directly from museum curators for collections that

128 had not yet been digitized with any of the aforementioned databases. The search term

129 "Micrurus fulvius", was used with no other qualifiers. Duplicate points were removed as

130 were localities found west of the Mississippi River (as those specimens are now recognized

131 as Micrurus tener), leaving a total of 1,074 unique records collected from 35 different

132 institutions (see the specific museum collections listed in Appendix S1). All points were

133 georeferenced and the precision of the locality data was estimated according to best

134 practices proposed by Chapman \& Wieczorek (2006). Records outside the timeframe of the

135 climate data (between 1950 - 2000) were removed (leaving n=747). Only points with an

136 uncertainty less than or equal to $5 \mathrm{~km}$ were retained for the model, which reduced the

137 number of records to 242. This reduced number of records provided substantial

138 geographic coverage of the entire range, with the exception of a small gap in both central

139 and western Florida. Because there were a high number of records from within the 1950-

1402000 timeframe, despite many of them not meeting our stringent requirements for spatial

141 accuracy, we included seven additional localities from these regions to provide complete

142 coverage of the range, leaving a total of $n=249$ records. Preliminary models showed using

143 occurrence data with lower uncertainty (i.e., less than $3 \mathrm{~km}$ ) greatly reduced the number of

144 locality points without improving model performance. Previous studies have also shown

145 that model performance is only minimally impacted at uncertainty thresholds below $5 \mathrm{~km}$

146 (Graham et al. 2008).

Datasets that are not collected via systematic sampling are often subject to biases

148 based on accessibility (Kadmon et al. 2004), dispersal ability, and level of scientific and

149 community interest (Fourcade et al. 2014). While we used some of the most robust 
150 available data for an elusive snake species (Franklin et al. 2009), bias can be reduced

151 through the background selection process previously discussed. In addition to background

152 selection, Fourcade et al. (2014) note that spatial filtering will further reduce bias

153 associated with non-systematic sampling. Therefore, the Spatially Rarefy Occurrence Data

154 for SDMs tool set within the SDMtoolbox (http://sdmtoolbox.org/) was used to classify and 155 spatially filter the climate variables into different homogenous areas and reduce the

156 number of points clustered around these homogenous zones (Brown et al. 2017).

157 SDMtoolbox is an ArcGIS extension that includes several tools to assist in running species

158 distribution models. This further reduced the number of points to 142 . Ten of these points

159 were found to be outside of the range of one or more environmental variable layers used

160 because they were located on islands that did not have bioclimate data available. Therefore,

161 Maxent did not use these points in the model, reducing the number of used occurrence

162 points to 132 . This number is well above the locality sample size at which Maxent has been

163 shown to be effective (Hernandez et al. 2006). In addition, the benefits of additional

164 occurrence points appear to plateau after 50 (Hernandez et al. 2006); however, some

165 studies disagree with 50 as either too conservative (Jiménez-Valverde \& Lobo 2007) or too

166 generous (Proosdij et al. 2015). In either case, the number of points we used was well

167 above this threshold.

For environmental data, we used 19 continuous bioclimatic variables downloaded

from WorldClim 1.4; these climate layers were generated using weather station data

compiled between 1950 and 2000 (Hijmans et al. 2005; www.worldclim.org, Table 1,

Appendix S2). These data are commonly used in Maxent modeling (as noted above), and 
173 the distribution of ecotherms. Additionally, as coral snakes have been shown to have a

174 preference for specific soil types (Steen et al, 2015) we used categorical soil type data from

175 the Harmonized World Soil Database created by the Food and Agriculture Organization of

176 the United Nations (FAO) and the International Institute for Applied Systems Analysis

177 (IIASA) (FAO/IIASA/ISRIC/ISSCAS/JRC 2012) (Table 1). We included the same soil layer in

178 both current and future climate models as soils can be expected to remain stable over these

179 short time frames. Raster grids for the bioclimatic variables were at a spatial resolution of

1802.5 arc-minutes (less than a $5 \mathrm{~km}^{2}$ resolution), and soil type data were scaled to match. This

181 resolution was chosen because it is close to the accuracy of the occurrence locality data

182 that were used, thereby maximizing the likelihood that conditions at the point of collection

183 are correctly portrayed while also maintaining the high resolution of the data (Anderson \&

184 Raza 2010).

The extent of the study area can also heavily influence model output (Elith et al. 2010). Large study regions can often lead to overfitting (Anderson \& Raza 2010), which lowers model transferability across time (Araújo \& Rahbek 2006). This is because Maxent uses 'pseudoabsence' points drawn randomly from throughout the study area and evaluates the model by comparing the environment at points where the species is known to be present with these pseudoabsence points (Phillips et al. 2006). Restricting the study extent to areas where the species being modeled could potentially occur, as opposed to areas far outside the range, restricts pseudoabsence points to areas where they are informative (Barbet-Massin et al. 2012). Thus, all 20 environmental variables were trimmed using ArcGIS 10.3 to include only those areas that overlap with the historical range of M. fulvius (NatureServe and IUCN 2007), with a buffer of $200 \mathrm{~km}$ around the 
196 known range. This buffer accomplishes two goals. First, the buffered region includes all the 197 current habitat where M. fulvius have been observed (including seven known localities that 198 occurred as far as $45 \mathrm{~km}$ outside of the range identified by the IUCN). This ensured that all 199 suitable habitat during the 1950-2000 time frame was used in the model. Second, including 200 an additional buffer beyond the known range captures all the potential area of future 201 suitable habitat (Fig. 2). This method of background selection produces more realistic 202 predictions than large study regions because it removes areas where species are unable to 203 disperse (Barve et al. 2011; Anderson \& Raza 2010).

Because the choice of environmental variables can influence model output, several independent models were run with different compositions of environmental variables (Table 1). Four strategies were used to select variables for each model. The first model was comprised of the full suite of variables, both bioclimatic and soil type (the Full model). However, many of the variables included in the Full model may have minimal influence and cause model overfitting (Baldwin 2009). Therefore, the results of the first model were used to identify variables with a significant ( $>5 \%$ ) contribution; these variables were used in the second model (the Reduced model). Finally, because of the potential for highly correlated variables, subsets of bioclimatic variables within 2 different correlation thresholds $-\mathrm{r}<0.7$

213 (Moderate Correlation model) and $\mathrm{r}<0.5$ (Low Correlation model) - were identified using 214 SDMtoolbox. The correlation threshold of 0.7 is commonly used in niche modeling and has 215 been well validated (Dormann et al. 2012). We also used 0.5 to determine if a more 216 rigorous threshold influenced model output. 
to 1.0 , maximum iterations 500 , and all models were replicated using 10 -fold crosspartitions of equal size $(\mathrm{k})$; models are then trained iteratively using k-1 partitions, while the final partition is retained for model evaluation (Merow et al. 2013; Radosavljevic \& Anderson 2013). Specifically, 10-fold cross-validation is a commonly used metric in the literature (e.g., Elith et al, 2011; Kearney et al. 2010). Jack-knifing was used to determine variable importance. The averages of these runs were used in all analyses. Results were visualized in ArcMap 10.3 using a WGS84 projection.

Two primary methods were used to assess model fit: area under the receiver operating characteristic (ROC) curve plots and true skill statistic (TSS). Area under the curve (AUC) is one of the most common statistics used for model evaluation. Although this metric has been criticized (Lobo et al. 2008), it is considered reliable enough for comparing models of a single species in the same area with the same predictor variables (Fourcade et al. 2014). True skill statistic is a threshold-dependent evaluation method that is based off of 237 Cohen's Kappa. The Kappa statistic is used in presence/absence models to calculate model accuracy normalized by the accuracy predicted by random chance (Allouche et al. 2006). 
239 TSS remains independent of prevalence and is therefore considered a robust test for

240 validation (Allouche et al. 2006).

241 2.2 Species Distribution Modeling - Future Climate

Data for future climate predictions were taken from the Consultative Group for International Agricultural Research (CGIAR) research program on Climate Change, Agriculture and Food Security (CCAFS). These raster grids were downloaded at an identical resolution to the current data (2.5 arc-minutes). Soil type data are assumed to remain stable through time even under the influence of climate change; because of this, soil type data used for current models (taken from the FAO/IIASA Harmonized World Soil Database) were used along with the projected future climate variables to comprise a full suite of variables. climate may follow in coming years. Each GCM comes from a different parent agency and represents a different scenario based on the chosen Representative Concentration Pathway (RCP) and model inputs. RCP is an emissions scenario that quantifies a potential climate future by projecting greenhouse gas trajectories (IPCC 2014). Smaller RCPs such as 2.6 have drastically lower projected greenhouse gas concentrations than larger RCPs such as 8.5. We selected an RCP of 4.5, which represents a moderate greenhouse gas mitigation scenario (Kopp et al. 2014). Under this scenario, the global mean surface temperature is likely to increase between $1.1^{\circ \mathrm{C}}$ to $2.6^{\circ \mathrm{C}}$ relative to the $1986-2005$ period by the end of the century (IPCC 2014). This RCP assumes moderate global efforts to reduce greenhouse gas 
260 emissions. If these reductions in emissions do not occur, this RCP may underestimate

261 future climate warming (Kopp et al. 2014).

262 Each Coupled Model Intercomparison Project (CMIP5) model configuration is the

263 product of a unique group of variables and therefore has its own benefits. Best practice is

264 to utilize multiple models because: (1) they allow a range of possible outcomes to be

265 evaluated and (2) similar outcomes from different models increase confidence (Collins et

266 al. 2013). Therefore, two CMIP5 configurations were selected: MIROC-ESM, a cooperative

267 effort by the University of Tokyo's Atmosphere and Ocean Research Institute, National

268 Institute for Environmental Studies, and Japan Agency for Marine-Earth Science and

269 Technology, and GISS-E2-R (NINT) from the Goddard Institute for Space Studies. Both

270 models used the same RCP as mentioned above.

Both CMIP5 configurations have different coupling compilations that result in different equilibrium climate sensitivity (ECS) and transient climate response (TCR) values: 4.7 ECS and 2.2 TCR for MIROC-ESM (Andrews et al. 2012) and 2.1 ECS and 1.5 TCR for GISS-E2-R (NINT) (Flato et al. 2013). Equilibrium climate sensitivity is a measure of the change in equilibrium global mean surface temperature after a doubling of atmospheric $\mathrm{CO}_{2}$ concentration, while transient climate response is a measure of expected warming at a 277 given time (Collins et al. 2013). Most models agree on a range for these values between 1.5 and 4.5 for ECS, and between 1 and 2.5 for TCR (Collins et al. 2013). Because MIROC-ESM is

279 above this range, it projects a dramatic change in mean surface temperature and is therefore considered more pessimistic than GISS-E2-R (NINT). 
analysis compares the environmental similarity of variables and identifies areas where one

or more environmental variables are outside of the training range and were implemented

with the Maxent Java Applet. Negative values indicate a novel climate, and the magnitude

indicate climate similarity and are scored out of 100 , with a score of 100 indicating that a

value is entirely non-novel (Elith et al. 2010).

\subsection{Model Change}

To quantify model change, results were first converted from continuous to binary

prediction. This step required the use of a threshold cutoff that defined areas with a

suitability greater than the threshold as "good" habitat and areas with a suitability less than

the threshold as "poor" habitat. For this study, the maximum training sum of sensitivity and specificity (Max SSS) threshold was chosen as it has been found to be a strong method for selecting thresholds with presence-only data (Liu et al. 2013). This threshold aims to maximize the summation of both sensitivity (true predicted presence) and specificity (true predicted absence). It is considered a strong choice when modeling for conservation purposes because the costs of omission (false negative) are greater than those of 
The Max SSS threshold for each model was relatively consistent across model type,

305

306

regardless of scenario (Table 2). The Low Correlation $(\mathrm{r}<0.5)$ model had the lowest threshold value at 0.2662 ; all other models had a threshold value of at least 0.3 .

\subsection{Prediction Success of Recent Occurrence Points}

Prediction success, or the percentage of occurrence points that the model correctly identifies as positive, was determined by the use of 20 additional occurrence points collected between 2001 and 2015 from museum records or directly from curators. These points were not used in the model constructions and thus provided an independent test of model results for data collected in between the two model timeframes (current and future). These points were displayed on a binary map of habitat suitability. Points that lay within the range of "suitable" habitat were predicted as true presences, while those that fell outside of the range were considered false negatives. Prediction success was then calculated by the equation p.s. $=a /(a+c)$ where $a=$ true positives and $c=$ false negatives. Additionally, we compared the logistic output at each site under both current and future climate models using a Wilcoxon signed-rank test.

\section{RESULTS}

\subsection{Species Distribution Modeling - Current Climate}

No significant difference was found between the AUC for the four model types (ANOVA; df=3, p=0.9253, Fig. 3). All AUCs fell between 0.81 and 0.83 (Table 2), which is considered a good fit model (Swets 1988). However, AUC values supplied by Maxent may differ from true AUC values because Maxent relies on background data and not true absence data, as noted in Proosdij et al. (2015). 
327 considered a good fit model (Landis \& Koch 1977). The Full model had the strongest TSS score (0.6314), both Reduced and Moderate Correlation models had similar values (0.5831 and 0.5733 ), and the Low Correlation model had the smallest TSS value. The performance of the Low Correlation model is likely due to the limited number of variables included $(n=4$ of 20) as well as a lack of highly influential variables that were included in the Reduced model, which also had few variables $(n=5)$ but a higher TSS score. in suitability predictions for all model types ( $\mathrm{r}>0.9$ ); however, the Reduced model identified a slightly greater extent of habitat suitability than the Full model. This is likely because the Reduced model was based off a small subset of the available environmental data (i.e., 5 out of the 20 variables because of our strict contribution requirements). Therefore, these models were the least constrained. As expected, the northern and central areas of Mississippi, Alabama, and Georgia were largely unsuitable aside from a small pocket of low suitability in central Alabama and south-central South Carolina. This small region in central Alabama is also highlighted by the IUCN range map. This is an area where M. fulvius has been known to occur historically, yet likely appears as only moderate to low suitability habitat in the models because we were only able to obtain two locality points from this region. Recent vouchered records of $M$. fulvius do not exist from this region in any

346 of the databases we searched. Although this lack of recent records may stem, in part, from

347 the fact that central Alabama remains one of the most herpetologically under surveyed 
348 regions in the southeastern United States, $M$. fulvius is known to be rare in this area (Mount 349 1975).

350 In addition, western and central North Carolina were unsuitable areas for M. fulvius.

351

352

353

354

355

356

357

358

359

360

361

362

363

364

365

366

367

368

369

\subsection{Species Distribution Modeling - Future Climate}

Under the GISS-E2-R (NINT) scenario, all model conditions gave similar results.

Here, we show the results of the Full and Reduced models as those were the top two performing models. Both model types showed an increase in the logistic value of suitable habitat and a northward expansion of suitable habitat conditions (Fig. 4). The southern to central portions of Alabama, Georgia, and South Carolina displayed moderate to high suitability in the Full model but not the Reduced model. Both models showed areas of unsuitability in central Mississippi, parts of west-central Alabama, northern Georgia, and western and central North Carolina.

As seen in the GISS-E2-R (NINT) models, both MIROC-ESM scenario models also showed an increase in suitable habitat and a northward expansion of suitable habitat conditions (Fig. 4). In both model types, nearly all of Florida was considered to be moderately to highly suitable habitat and the majority of the northern boundary of our study region was predicted to be unsuitable.

\subsection{Climate Novelty}

MESS analysis identified multiple areas where no-analog or novel climates were present, which varied among models, years, and model types (Fig. 5). MIROC-ESM 2050 predicted a high degree of climate similarity in two of the four models (Low and Reduced); the Full and Moderate models, however, displayed almost no climate similarity. This would 
370 indicate that one or more of the future climate layers used in only these models may fall

371 outside of the ranges seen in current times (1950-2000). The results from MIROC-ESM are

372 similar to those obtained with GISS-E2-R (NINT) models (Fig. 5), where the Reduced and

373 Low Correlation models show a higher degree of climate similarity than the Full and

374 Moderate models.

375

376

377

378

379

380

381

382

383

384

385

386

387

388

389

390

391

\subsection{Model Change}

All models showed a northward expansion of various degrees from current conditions to 2050, consistent with our hypothesis (Fig. 6). Among the MIROC-ESM models, the Reduced model was the most conservative with predicting expansion. Similar results were found among GISS-E2-R (NINT) models. Areas of retraction were minimal and outweighed by areas of expansion.

As mentioned above, the Full model had the highest TSS score while the AUC scores were nearly identical across all four models. However, based on the effects of clamping and the MESS analysis, the Reduced model type is less biased by no-analog climate. The difference between the results of these two model types leads to slightly different predictions: the Reduced model predicts less range expansion than the Full model and is therefore more conservative.

\subsection{Description of Suitable Environment}

Based on the differential results in identifying central peninsular Florida as suitable as well as the jack-knifing results, we predict that Temperature Seasonality, Mean Temperature of Coldest Quarter, Precipitation of Driest Month, Precipitation of Warmest Quarter, or some combination therein is highly influential for determining habitat 
392 suitability. Soil type also had a significant influence on the output of the models. Because $M$.

393 fulvius tends to inhabit areas of longleaf pine and scrub oaks, soil types that foster such

394 vegetation would likely indicate more suitable habitat.

395

396

397

398

399

400

401

402

403

404

405

406

407

408

409

410

411

412

\subsection{Prediction Success of Recent Occurrence Points}

The ability of the current climate models (1950-2000) to predict recently collected records ( $n=20$, collected between 2001 and 2015) was moderate across all four model types $(0.5<$ p.s. < 0.75). However, the 2050 models - both MIROC-ESM and GISS-E2-R $($ NINT) - had much higher prediction success $(0.8<$ p.s. $=1)$. Further comparing the logistic output at each site under current and 2050 conditions showed that there was a significant increase in habitat suitability under future climate conditions (MIROC-ESM 2050: $n=20, W=2, p<0.001 ;$ GISS-E2-R (NINT) 2050: $n=20, W=2, p<0.001)$.

\section{DISCUSSION}

Current Maxent models suggest coral snake distributions are restricted to the southeastern United States, with only very limited areas of high habitat suitability; the majority of high to moderate habitat suitability areas are restricted to Florida. These results align well with the current known distribution of coral snakes (IUCN 2007). Also, all four current climate models show relatively consistent geographic predictions. The largest region of difference between the models is in the southernmost tip of Florida which is shown as low habitat suitability by the Full model but more moderate suitability by the Low Correlation models; the other two models were intermediate between the Full and Low Correlation models. 
414 identified as moderate habitat suitability by the current climate models, and a slight expansion of suitable habitat along coastal regions. Both the GISS-E2-R (NINT) and MIROCESM models show similar geographic patterns. The Full models for both future climate change scenarios show more extensive range expansion than Reduced models. For the Full models, MIROC-ESM showed slightly greater range expansion than the equivalent GISS-

E2_R (NINT) models; the extent of range expansion was more similar between MIROC-ESM and GISS-E2_R (NINT) for the Reduced models (Fig. 6). It is important to note that both the GISS-E2_R and MIROC-ESM climate data assume some global mitigation efforts will slow CO2 emissions (Kopp et al. 2014). If no mitigation efforts occur, this RCP undoubtedly underestimates warming. As ectotherms are highly reliant on temperature, climate change is predicted to increase the potential distribution of many temperate reptile species in the Northern Hemisphere (Currie 2001; Hansen et al. 2001; Araújo et al. 2006). In particular, as M. fulvius already occurs at relatively high abundances in sub-tropical Florida, the increase in predicted habitat suitability in much of the Southeast as it warms is not surprising. the range of current climate conditions, suggesting the presence of no-analog or novel environments within the Southeast in the future. Although habitats across the Southeast will warm, the extent of warming in the future will likely exceed recent maximum temperature conditions (Fig. 5). Thus, these results must be interpreted with caution.

433 These results are especially relevant as many reptile species are often not capable of optimal performance at the high end of their thermal tolerance and perform best at a lower temperature known as the "thermal optimum" (Clusella-Trullas et al. 2011). It is unlikely 
436 that the upper limit will be reached, but it is possible that the thermal optimum may be 437 exceeded which may have significant impacts on the behavior of reptile species. Although 438 thermal data are lacking on wild individuals of $M$. fulvius, their fossorial tendencies and diel 439 activity patterns (early morning and late evening) suggest that their thermal optimum 440 could likely be exceeded by future warming in several areas of their range. Better 441 physiological data that would allow an integration of mechanistic models with these 442 correlative models (e.g., Ceia-Hasse et al. 2014) is clearly needed. While climate change is often assumed to be a future issue, in reality it is likely

444 already mediating range shifts and other potentially adverse species responses (Parmesan 445 \& Yohe 2003; Chen et al. 2011). The increased prediction success of the future 2050 446 models, both MIROC-ESM and GISS-E2-R (NINT), indicates that climate may already be 447 changing, resulting in range shifts in M. fulvius. This work suggests that studies using 448 Maxent to make conservation decisions should strongly consider using future climate 449 models in addition to models of the current climate conditions. This is particularly 450 important for predicting the poleward range limits for ectothermic species that may 451 already be undergoing significant range shifts, as these limits are often dependent on 452 abiotic factors (Cunningham et al. 2016). Temperature and precipitation are the most 453 common variables included in Maxent models, and most of the 19 bioclimatic variables have 454 been used in more than 1000 published models to date (reviewed by Bradie \& Leung 455 2017). These models may be misleading if only current climate is considered. Thus, we 456 encourage future studies to include future climate projections as these predicted climate 457 layers may improve model performance over using only current climate data. 
Although the impact of climate change on shifts in species distributions has now

459 been well documented, the impacts of climate change on the distribution of reptiles, and 460 particularly snakes, remain understudied (but see Araújo et al. 2006). Given that climate 461 conditions from 2050 already better predict the distribution of $M$. fulvius than 'current' 462 climate conditions, systematic surveys at northern range edges for $M$. fulvius and other 463 snake species will likely yield valuable information on the rate of range shifts in response 464 to climate change. This work has important conservation implications for M. fulvius. M. fulvius is 466 already infrequently encountered throughout its range and is extremely rare along its northern range limit. In North and South Carolina, where M. fulvius is currently at the range limit, habitat is expected to increase in suitability. Yet, high habitat fragmentation across the southeastern United States may limit the ability of this species to recover in these states where it is of conservation concern. The growing market for wood pellets in Europe could threaten US longleaf pine forests (Tarr et al, 2017), the preferred forest type of M. fulvius. In addition, an increasing demand for pine straw within the United States has left much of the

473 longleaf pine forest that remains devoid of the leaf litter layer on which many fossorial 474 reptiles, such as $M$. fulvius, depend. Thus, dispersal ability will be critical in driving whether or not any species will be capable of occupying newly suitable habitat (Araújo et al. 2006). In addition to habitat fragmentation, habitat preferences for environmental axes not

477 included here may also limit this species' ability to respond as predicted to climate change. 
480 kingsnake (Lampropeltis elapsoides) and the scarlet snake (Cemophora coccinea) (Fig. 1).

481 Both mimic species occur well beyond the current range of M. fulvius. In allopatry, both

482 mimic species have more red and less black on their dorsum than M. fulvius (Harper and

483 Pfennig 2008; Akcali and Pfennig 2017), making them poor mimics. However, this

484 breakdown of mimicry in allopatry is favored by predator-mediated selection: clay replicas

485 of snakes that had similar amounts of red and black as $M$. fulvius were attacked more often

486 in allopatry than the local phenotype with more red (Pfennig et al. 2007). In contrast,

487 mimics that co-occur with M. fulvius at the edge of its range (e.g., in North Carolina)

488 resemble it more precisely; in edge sympatry, there were fewer attacks on this phenotype

489 than the redder allopatric one (Harper and Pfennig 2007; Kikuchi and Pfennig 2010). Thus,

490 the migration of $M$. fulvius into previously uninhabited regions should facilitate the

491 evolution of precise mimicry among local mimics. How rapidly precise mimicry evolves will

492 depend on such factors as the generation times of predators and mimics, the standing

493 variation in color pattern among mimics, the extent of gene flow between mimics from

494 historical sympatry and mimics from 'novel' sympatry, and the strength of selection for

495 precise mimics.

\section{Acknowledgments}

497 The authors would like to thank all curators whose published data were used for this

498 research. Additional thanks goes to Jeff Beane, Herpetology Collections Manager of the

499 North Carolina Museum of Natural Sciences, as well as the Georgia Museum of Natural

500 History and the Mississippi Museum of Natural History for providing additional non-

501 indexed data for this research. Finally, the authors would like to thank Michael McQuillan,

502 Gregory Haenel, and David Vandermast for their comments on the manuscript. 
504

505

506

507

508

509

510

511

512

513

514

515

516

517

518

519

520

521

522

523

\section{REFERENCES}

Akcali, C.K. \& Pfennig, D.W. (2017) Geographic variation in mimetic precision among different species of coral snake mimics. Journal of Evolutionary Biology, 30, 14201428.

Allouche, O., Tsoar, A. \& Kadmon, R. (2006) Assessing the accuracy of species distribution models: prevalence, kappa and the true skill statistic (TSS). Journal of Applied Ecology, 43, 1223-1232.

Anderson, R.P. \& Raza, A. (2010) The effect of the extent of the study region on GIS models of species geographic distributions and estimates of niche evolution: preliminary tests with montane rodents (genus Nephelomys) in Venezuela. Journal of Biogeography, 37, 1378-1393.

Andrews, T., Gregory, J.M., Webb, M.J. \& Taylor, K.E. (2012) Forcing, feedbacks and climate sensitivity in CMIP5 coupled atmosphere-ocean climate models. Geophysical Research Letters, 39, 1-7.

Araújo, M.B. \& Rahbek, C. (2006) How does climate change affect biodiversity? Science, 313, 1396-1397.

Araújo, M.B., Pearson, R.G., Thuiller, W. \& Erhard, M. (2005) Validation of species-climate impact models under climate change. Global Change Biology, 11, 1504-1513.

Araújo, M.B., Thuiller, W., \& Pearson, R.G. (2006) Climate warming and the decline of amphibians and reptiles in Europe. Journal of Biogeography, 33, 1712-1728. 
524 Baldwin, R.A. (2009) Use of Maximum Entropy Modeling in wildlife research. Entropy, 11, 854-866.

526

527

528

529

530

531

532

533

534

535

536

537

538

539

540

541

542

543

544

545

Barbet-Massin, M., Jiguet, F., Albert, C.H. \& Thuiller, W. (2012) Selecting pseudo-absences for species distribution models: how, where and how many? Methods in Ecology and Evolution, 3, 327-338.

Barve, N., Barve, V., Jiménez-Valverde, A., Lira-Noriega, A., Maher, S.P., Townsend Peterson, A., Soberón, J. \& Villalobos, F. (2011) The crucial role of the accessible area in ecological niche modeling and species distribution modeling. Ecological Modeling, 222, 1810-1819.

Beane, J.C., Braswell, A.I., Mitchell, J.C., Palmer, W.M. \& Harrison III, J.R. (2010) Amphibians \& reptiles of the Carolinas and Virginia, 2nd edn. The University of North Carolina Press, Chapel Hill.

Böhm, M., Collen, B., Baillie, J.E.M., Bowles, P., Chanson, J., Cox, N., Hammerson, G., Hoffmann, M., Livingstone, S.R., Ram, M., Rhodin, A.G.J., Stuart, S.N., van Dijk, P.P., Young, B.E., Afuang, L.E., Aghasyan, A., García, A., Aguilar, C., Ajtic, R., Akarsu, F., Alencar, L.R.V., Allison, A., Ananjeva, N., Anderson, S., Andrén, C., Ariano-Sánchez, D., Arredondo, J.C., Auliya, M., Austin, C.C., Avci, A., Baker, P.J., Barreto-Lima, A.F., BarrioAmorós, C.L., Basu, D., Bates, M.F., Batistella, A., Bauer, A., Bennett, D., Bohme, W., Broadlet, D., Brown, R., Burgess, J., Captain, A., Carreira, S., Castañeda, M.d.R., Castro, F., Ctenazzi, A., Cedeño-Vazquez, J.R., Chapple, D.G., Cheylan, M., Cisneros-Heredia, D.F., Cogalniceanu, D., Cogger, H., Corti, C., Costa, G.C., Couper, P.J., Courtney, T., Crnobrnja-Isailovic, J., Crochet, P., Crother, B., Cruz, F., Daltry, J.C., Daniels, R.J.R. Das, 
I., de Silva, A., Diesmos, A.C., Dirksen, L., Doan, T.M., Dodd Jr., C.K., Doody, J.S., Dorcas, Ineich, I., Iverson, J., Jaksic, F.M., Jenkins, R., Joger, U., Jose, R., Kaska, Y., Kaya, U., Keogh, J.S., Kohler, G., Kuchling, G., Kumultas, Y., Kwet, Y., La Marca, E., Lamar, W., Lane, A., Lardner, B., Latta, C., Latta, G., Lau, M., Lavin, P., Lawson, D., LeBreton, M., Lehr, E., Limpus, D., Lipczynski, N., Lobo, A.S., López-Luna, M.A., Luiselli, L., Lukoschek, V., Lundberg, M., Lymberakis, P., Macey, R., Magnusson, W.E., Mahler, D.L. Mahotra, A., Mariaux, J., Maritz, B., Marques, O.A.V., Márquez, R., Martins, M., Masterson, G., Mateo, J.A., Mathew, R., Mathews, N., Mayer, G., McCranie, J.R., Measey, 560 G.J., Mendoza-Quijano, F., Menegon, M., Métrailler, S., Milton, D.A., Montgomery, C., Morato, S.A.A., Mott, T., Muñoz-Alonso, A., Murphy, J., Nguyen, T.Q., Nilson, G., Noqueira, C., Núñez, H., Orlov, N., Ota, H., Ottenwalder, J., Papernfuss, T., Pasachnik, S., Passos, P., Pauwels, O.S.G., Pérez-Buitrago, N., Pérez-Mellado, V., Pianka, E.R., Pleguezuelos, J., Pollock, C., Ponce-Campos, P., Powell, R., Pupin, F., Quintero Díaz, Rico, E.L., Riservato, E., Rivas, G., da Rocha, P.L.B., Rödel, M. Rodríguez Schettino, L., Roosenburg, W.M., Ross, J.P., Sadek, R., Sanders, K., Santos-Barrera, G., Schleich, H.H., 
569

570

571

572

573

574

575

576

577

578

579

580

581

582

583

584

585

586

587

588

T., Somaweera, R., Spawls, S., Stafford, P., Stuebing, R., Sweet, S., S, E., Temple, H.J., Tognelli, M.F., Tolley, K., Tolson, P.J., Tuniyev, B., Tuniyev, S, Üzüm, N., van Buurt, G., Van Sluys, M., Velasco, A., Vences, M., Veselý, M., Vinke, S., Vinke, T., Vogel, G., Vogrin, M., Vogt, R.C., Wearn, O.R., Werner, Y.L., Whiting, M.J., Wiewandt, T., Wilkinson, J., Wilson, B., Wren, S., Zamin, T., Zhou, K. \& Zug, G. (2013) The conservation status of the world's reptiles. Biological Conservation, 157, 372-385.

Bradie, J. \& Leung, B. (2017) A quantitative synthesis of the importance of variables used in Maxent species distribution models. The Journal of Biogeography, 44, 1344-1361.

Brown, J. L., Bennett, J. R. \& French, C. M. (2017) SDMtoolbox 2.0: the next generation Python-based GIS toolkit for landscape genetic, biogeographic and species distribution model analyses. PeerJ 5:e4095; DOI 10.7717/peerj.4095.

Ceia-Hasse, A., Sinervo, B., Vicente, L., \& Pereira, H. M. (2014) Integrating ecophysiological models into species distribution projections of European reptile range shifts in response to climate change. Ecography, 37, 679-688.

Chapin III, F., Zavaleta, E., Eviner, V., Naylor, R., Vitousek, P., Reynolds, H., Hooper, D., Lavorel, S., Sala, O., Hobbie, S., Mack, M. \& Díaz, S. (2000) Consequences of changing biodiversity. Nature, 405, 234-242.

Chapman, A.D. \& Wieczorek, J. (2006) Guide to Best Practices for Georeferencing. Global Biodiversity Information Facility, Copenhagen.

http://www.gbif.org/orc/?doc_id=1288. 
589 Chen, I-Ching, Hill, J. K., Ohlemuller, R., Roy, D. B., \& Thomas, C. D. 2011. Rapid range shifts

590 of species associated with high levels of climate warming. Science, 333, 1024-1026.

591 Christoffel, R.A., \& Lepcyzk, C.A. (2012) Representation of herpetofauna in wildlife research 592 journals. The Journal of Wildlife Management, 76, 661-669.

593 Chunco, A. J., Phimmachak, S., Sivongxay, N. \& Stuart, B.I. (2013) Predicting environmental suitability for a rare and threatened species (Lao Newt, Laotriton laoensis) using 595 validated species distribution models. PLoS One, 8, e59853.

596

597

598

599

600

601

602

603

604

605

606

607

608

609
Clusellas-Trullas, S., Blackburn, T.M. \& Chown, S.L. (2011) Climatic predictors of temperature performance curve parameters in ectotherms imply complex responses to climate change. The American Naturalist, 177, 738-751.

Collins, M., Knutti, R., Arblaster, J., Dufresne, J.L., Fichefet, T., Friedlingstein, P., Gao, X., Gutowski, W.J., Johns, T., Krinner, G., Shongwe, M, Tebaldi, C., Weaver, A.J. \& Wehner, M. (2013) Long-term Climate Change: Projections, Commitments and Irreversibility. Climate Change 2013: The Physical Science Basis. Contribution of Working Group I to the Fifth Assessment Report of the Intergovernmental Panel on Climate Change (ed. by Stocker, T.F., D. Qin, G.-K. Plattner, M. Tignor, S.K. Allen, J. Boschung, A. Nauels, Y. Xia, V. Bex and P.M. Midgley), pp. 1029-1136. Cambridge University Press, Cambridge.

Cunningham, H.R., Rissler, L.J., Buckley, L.B. \& Urban, M.C. (2016) Abiotic and biotic constraints across reptile and amphibian ranges. Ecography, 39, 1-8.

Currie, D. J. (2001) Projected effects of climate change on patterns of vertebrate and tree species richness in the conterminous United States. Ecosystems, 4, 216-225. 
610 Davey, G.C.L., McDonald, A.S., Hirisave, U., Prabhu, G.G., Iwawaki, S., Jim, C.I., Mercekbach, H., 611 de Jong, P.J., Leung, P.W.L. \& Reimann, B.C. (1998) A cross-cultural study of animal fears. Behavior Research and Therapy, 36, 735-750.

613

614

615

616

617

618

619

620

621

622

623

624

625

626

627

628

629

630

Dormann, C.F., Elith, J., Bacher, S., Buchmann, C., Carl, G., Carre, G., Garciea Marquez, J.R., Gruber, B., Lafourcade, B., Laitao, P.J., Menkemuller, T., McClean, C., Osborne, P.E., Reineking, B., Schroder, B., Skidmore, A.K., Zurell, D. \& Lautenbach, S. (2013) Collinearity: a review of methods to deal with it and a simulation study evaluating their performance. Ecography, 36, 27-46.

Elith, J., Graham, C.H., Anderson, R.P., Dudík, M., Ferrier, S., Guisan, A., Hijmans, R.J., Huettmann, F., Leathwick, J.R., Lehmann, A., Loiselle, B.A., Manion, G., Moritz, C., Nakamura, M., Nakazawa, Y., Overton, M.M., Townsend Peterson, A., Phillips, S.J., Peterson, K., Scachetti-Pereira, R., Schapire, R.E., Soberón, J., Williams, S., Wisz, M.S. \& Zimmermann, N.E. (2006) Novel methods improve prediction of species' distributions from occurrence data. Ecography, 29, 129-151.

Elith, J., Kearney, M. \& Phillips, S. (2010) The art of modeling range-shifting species. Methods in Ecology and Evolution, 1, 330-342.

Elith, J., Phillips, S.J., Hastie, T., Dudík, M., Chee, Y.E. \& Yates, C.J. (2011) A statistical explanation of Maxent for ecologists. Diversity and Distributions, 17, 43-47.

FAO/IIASA/ISRIC/ISSCAS/JRC. 2012. Harmonized World Soil Database (version 1.2). <http://webarchive.iiasa.ac.at/Research/LUC/External-World-soildatabase/HTML/index.html?sb?1?tm Data downloaded from 
631

632

633

634

635

636

637

638

639

640

641

642

643

644

645

646

647

648

649

650

651

http://www.arcgis.com/home/item.html?id=1d16ed2a0aa24ab39e5ee6c49196588 3

Fitzpatrick, M.C., Grove, A.D., Sanders, N.J. \& Dunn, R.R. (2008) Climate change, plant migration, and range collapse in a global biodiversity hotspot: The Banksia (Proteaceae) of Western Australia. Global Change Biology, 14, 1337-1352.

Flato, G., Marotzke, J., Abiodum, B., Braconnot, P., Chou, S.C., Collins, W., Cox, P., Drioech, F., Emori, S., Eyring, V., Forest, C., Gleckler, P., Guilyardi, E., Jakob, C., Kattsov, V., Reason, C. \& Rummukainen, M. (2013) Evaluation of Climate Models. Climate Change 2013: The Physical Science Basis. Contribution of Working Group I to the Fifth Assessment Report of the Intergovernmental Panel on Climate Change (ed. by T.F. Stocker, D. Qin, G.-K. Plattner, M. Tignor, S.K. Allen, J. Boschung, A. Nauels, Y. Xia, V. Bex and P.M. Midgley), pp. 13-14. Cambridge University Press, Cambridge.

Fourcade, Y., Engler, J.O., Rodder, D. \& Secondi, J. (2014) Mapping species distributions with Maxent using a geographically biased sample of presence data: a performance assessment of methods for correcting sampling bias. PLoS One, 9, e97122.

Franklin, J., Wejnert, K.E., Hathaway, S.A., Rochester, C.J. \& Fisher, R.N. (2009) Effect of species rarity on the accuracy of species distribution models for reptiles and amphibians in southern California. Diversity and Distributions, 15, 167-177.

Gardner, T.A., Barlow, J., \& Peres, C.A. (2007) Paradox, presumption and pitfalls in conservation biology: the importance of habitat change for amphibians and reptiles. Biological Conservation, 138, 166-179. 
652 Gilman, S.E., Urban, M.C., Tewksbury, J., Gilchrist, G.W., \& Holt, R.D. (2010) A framework for 653 community interactions under climate change. Trends in Ecology and Evolution, 25, $654 \quad 325-331$.

655 Girons, H.S. (1982) Reproductive cycles of male snakes and their relationships with climate 656 and female reproductive cycles. Herpetologica, 38, 5-16.

657 Graham, C.H., Elith, J., Hijmans, R.J., Guisan, A., Peterson, A.T., Loiselle, B.A. \& The NCEAS 658 Predicting Species Distributions Working Group. (2008) The influence of spatial 659 errors in species occurrence data used in distribution models. Journal of Applied $660 \quad$ Ecology, 45, 239-247.

661 Graham, C.H., Ferrier, S., Huettmen, F., Moritz, C. \& Peterson, A.T. (2004) New developments 662 in museum-based informatics and application in biodiversity analysis. Trends in $663 \quad$ Ecology and Evolution, 19, 497-503.

664 Gu, W. \& Swihart, R.K. (2004) Absent or undetected? Effects of non-detection of species 665 occurrence on wildlife-habitat models. Biological Conservation, 116, 195-203.

666 Guimaraes, M., Munguia-Steyer, R., Doherty Jr., P.F., Martins, M. \& Sawaya, R.J. (2014)

667 Population dynamics of the critically endangered golden lancehead pitviper, 668 Bothrops insularis: stability or decline? PLOS ONE, 9, 1-7.

669 Guisan, A. \& Thuiller, W. (2005) Predicting species distribution: offering more than simple 670 habitat models. Ecology Letters, 8, 993-1009. 
671 Hammerson, G.A. (2007) Micrurus fulvius. The IUCN Red List of Threatened Species 2007:

672 e.T64025A12737582. http://dx.doi.org/10.2305/IUCN.UK.2007.RLTS.T64025A127

673 37582.en. Downloaded on 14 January 2016.

674

675

676

677

678

679

680

681

682

683

684

685

686

687

688

689

690

Hansen, A.J., Neilson, R.P., Dale, V.H., Flather, C.H., Iverson, L.R., Currie, D.J., Shafer, S., Cook, R. \& Bartlein, P.J. (2001) Global change in forests: responses of species, communities and biomes. BioScience, 51, 765-779.

Harper, G. R. \& Pfennig, D.W. (2007) Mimicry on the edge: why do mimics vary in resemblance to their model in difference parts of their geographic range? Proceedings of the Royal Society B, 274, 1955-1961.

Hernandez, P.A., Graham, C.H., Master, L.L. \& Albert, D.L. (2006) The effect of sample size and species characteristics on performance of different species distribution modeling methods. Ecography, 29, 773-785.

Hellmann, J.J, Byers, J.E., Bierwagen, B.G. \& Dukes, J.S. (2008) Five potential consequences of climate change for invasive species. Conservation Biology, 22, 534-543.

Hijmans, R.J., Camerson, S.E., Parra, J.L., Jones, P.G. \& Jarvis, A. (2005) Very high resolution interpolated climate surfaces for global land areas. International Journal of Climatology, 25, 1965-1978.

Hole, D.G., Huntley, B., Arinaitwe, J., Butchart, S.H.M., Collingham, Y.C., Fishpool, L.D.C, Pain, D.J. \& Willis, S.G. (2011) Toward a management framework for networks of protected areas in the face of climate change. Conservation Biology, 25, 305-315. 
691 Huey, R.B. (1982) Temperature, physiology, and the ecology of reptiles. Biology of the 692 Reptilia, 12, 25-91.

693

694

695

696

697

698

699

700

701

702

703

704

705

706

707

708

709

710

711

Huey, R.B., Deutsch, C.A., Tewksbury, J.J., Vitt, L.J., Hertz, P.E., Alvarez, H.J. \& Garland, T. (2009) Why tropical forest lizards are vulnerable to climate warming. Proceedings of the Royal Society of London, 276, 1939-1948.

Hughes, L. (2000) Biological consequences of global warming: Is the signal already apparent?. Trends in Ecology and Evolution, 15, 56-61.

Intergovernmental Panel on Climate Change. (2007) Climate change 2007: The physical science basis. Contribution of working group I to the Fourth Assessment Report of the Intergovernmental Panel on Climate Change (ed. by S. Solomon, D. Qin, M. Manning, Z. Chen, M. Marquis, K.B., Averyt, M. Tignor, and H.L. Miller), pp. 1-996. Cambridge, United Kingdom.

Intergovernmental Panel on Climate Change. (2014) Climate change 2014: synthesis report. Contribution of Working Groups I, II and III to the Fifth Assessment Report of the Intergovernmental Panel on Climate Change (ed. by Core Writing Team, R.K. Pachauri and L.A. Meyer), pp. 1-151. Geneva, Switzerland.

Jackson, D. R., and Franz, R. 1981. Ecology of the eastern coral snake (Micrurus fulvius) in northern Florida. Herpetologica 37, 213-228.

Jenkins, C.L., Peterson, C.R. \& Kingsbury, B.A. (2009) Modeling snake distribution and habitat. Snakes: ecology and conservation (ed. by S.J. Mullin and R.A. Siegel), pp. 123148. Cornell University Press, Ithaca. 
712 Jiménez-Valverde, A., \& Lobo, J.M. (2007) Threshold criteria for conversion of probability of species presence to either-or presence-absence. Acta Oecologica, 31, 361-369.

714

715

716

717

718

719

720

721

722

723

724

725

726

727

728

729

730

731

Jiménez-Valverde, A., Lobo, J.M. \& Hortal, J. (2008) Not as good as they seem: the importance of concepts in species distribution modeling. Diversity and Distributions, 14, 885-890.

Kadmon, R., Farber, O. \& Danin, A. (2004) Effect of roadside bias on the accuracy of predictive maps produced by bioclimatic models. Ecological Applications, 14, 401413.

Karl, T.R., Arguez, A., Huang, B., Lawrimore, J.H., McMahon, J.R., Menne, M.J., Peterson, T.C., Vose, R.S. \& Zhang, H.M. (2015) Possible artifacts of data biases in the recent global surface warming hiatus. Science, 348, 1469-1472.

Kearney, M. R., Wintle, B. A., Porter, W. P. (2010). Correlative and mechanistic models for species distribution provide congruent forecasts under climate change. Conservation Letters, 3, 203-213.

Kopp, R.E., Rasmussen, D.J., Mastrandrea, M., Muir-Wood, Wilson, P., Larsen, K., Hsiang, S., Jina, A., Rising, J., Delgado, M., Mohan, S., Houser, T. (2014) American Climate Prospectus: Economic Risks in the United States. Rhodium Group LLC. New York, Ney York.

Landis, J. R. \& Koch, G.G. (1977) The measurement of observer agreement for categorical data. Biometrics, 33, 159-174. 
732 Liu, C., White, M. \& Newell G. (2013) Selecting thresholds for the prediction of species

733 occurrence with presence-only data. Journal of Biogeography, 40, 778-789.

734 Lobo, J. M., Jiménez-Valverde, A. \& Real, R. (2008) AUC: a misleading measure of the

735

736

737

738

739

740

741

742

743

744

745

746

747

748

749

750

751 performance of predictive distribution models. Global Ecology and Biogeography, $17,145-151$.

Loiselle, B.A., Howell, C.A., Graham, C.H., Goerck, J.M., Brooks, T., Smith, K.G. \& Williams, P.H. (2003) Avoiding pitfalls of using species distribution models in conservation planning. Conservation Biology, 17, 1591-1600.

Merow, C., Smith, M. J. \& Silander, J. A. 2013. A practical guide to MaxEnt for modeling species' distributions: what it does, and why inputs and settings matter. Ecography, 36, 1058-1069.

Mount, R.H. (1975) The Reptiles and Amphibians of Alabama. Auburn University Agricultural Experiment Station, Auburn.

NatureServe and IUCN (International Union for Conservation of Nature) (2007) Micrurus fulvius. The IUCN Red List of Threatened Species. http://www.iucnredlist.org. Downloaded on 29 September 2015.

Nori, J., Carrasco, P.A. \& Leynaud, G.C. (2014) Venomous snakes and climate change: ophidism as a dynamic problem. Climate Change, 122, 67-80.

North Carolina Wildlife Resources Commission. (2014) Protected wildlife species of North Carolina. 
Parmesan, C. (2006) Ecological and evolutionary responses to recent climate change. Annual Review of Ecology, Evolution and Systematics, 37, 637-669.

756

757

758

759

760

761

762

763

764

765

766

767

768

769

770

771

Parmesan, C. \& Yohe, G. (2003) A globally coherent fingerprint of climate change impacts across natural systems. Nature, 421, 37-42.

Pearson, R.G. \& Dawson, T.P. (2003) Predicting the impacts of climate change on the distribution of species: are bioclimate envelope models useful?. Global Ecology and Biogeography, 12, 361-371.

Phillips, S. J. A brief tutorial on Maxent, versions: 3.3.1. Available online: http://www.cs.princeton.edu/ sschapire/maxent/tutorial/tutorial.doc.

Phillips, S. J., Dudík, M. \& Schapire, R.E. (2004) A maximum entropy approach to species distribution modeling. Proceedings of the Twenty-First International Conference on Machine Learning, 655-662.

Phillips, S. J., Anderson, R. P., Schapire, R. E. (2006) Maximum entropy modeling of species geographic distributions. Ecological Modelling 190, 231-259.

Phillips, S.J. \& Dudík, M. (2008) Modeling of species distributions with Maxent: new extensions and a comprehensive evaluation. Ecography, 31, 161-175.

Pounds, A. J., Bustamante, M.R., Coloma, L.A., Consuegra, A., Fogden, M.P.L., Foster, P.N., la Marca, E., Masters, K.L., Merino-Viteri, A., Puschendorf, R., Ron, S.R., Sánchez- 
772

773

774

775

776

777

778

779

780

781

782

783

784

785

786

787

788

789

790

791

792

Azofeifa, G.A., Still, C.J. \& Young, B.E. (2006) Widespread amphibian extinctions from epidemic disease driven by global warming. Nature, 439, 161-167.

Proosdij, A.S.J., Sosef, M.S.M., Wieringa, J.J. \& Raes, N. (2016) Minimum required number of specimen records to develop accurate species distribution models. Ecography, 39, $542-552$.

Radosavljevic, A. \& Anderson, R. P. 2013. Making better Maxent models of species distributions: complexity, overfitting and evaluation. Journal of Biogeography, 41, 629-643.

Reading, C.J., Luiselli, L.M., Akani, G.C., Bonnet, X., Amori, G., Ballouard, J.M., Fillippi, E., Naulleau, G., Pearson, D. \& Rugiero, L. (2010) Are snake populations in widespread decline?. Biology Letters, 6, 777-780.

Segura, C., Feriche, M., Pleguezuelos, J.M. \& Santos, X. (2007) Specialist and generalist species in habitat use: Implications for conservation assessment in snakes. Journal of Natural History, 41, 2765-2774.

South Carolina Department of Natural Resources. (2014) SC Rare, Threatened \& Endangered Species Inventory. http://dnr.sc.gov/species/index.html.

Steen, D. A., Barbour, M., McClure, C. J. W., Wray, K. P., Macey, J. N., Stevenson, D. J., 2015. Landscape scale habitat section of Harlequin Coralsnakes (Micrurus fulvius) in three large, protected areas in the southeastern United States. Copeia 103, 1037-1042.

Sunday, J.M., Bates, A.E. \& Dulvy, N.K. (2012) Thermal tolerances and the global redistribution of animals. Nature Climate Change, 2, 686-690. 
793 Swets, J.A. (1988) Measuring the accuracy of diagnostic systems. Science, 240, 1285-93.

794 Tarr, N. M., Rubino, M. J., Costanza, J. K., McKerrow, A. J., Collazo, J. A., Abt, R. C. (2017)

795 Projected gains and losses of wildlife habitat from bioenergy-induced landscape 796 change. Global Change Biology Bioenergy, 9: 909-923.

797 Thomas, C.D., Cameron, A., Green, R.E., Bakkenes, M., Beaumont, L.J., Collingham, Y.C., 798 Erasmus, B.F.N, de Siqueira, M.F., Grainger, A., Hannah, L., Hughes, L., Huntley, B., van 799 Jaarsveld, A.S., Midgley, G.F., Miles, L., Ortega-Huerta, M.A., Townsend Peterson, A., 800 801 Phillips, O.L. \& Williams, S.E. (2004) Extinction risk from climate change. Nature, 802 803

Tylianakis, J.M., Didham, R.K., Bascompte, J. \& Wardle, D.A. (2008) Global change and 427, $145-148$.

804

805

806

807

808

809

810

811

812

813 species interactions in terrestrial ecosystems. Ecology Letters, 11, 1352-1363.

Urbina-Cardona, J.N. \& Flores-Villela, O. (2010) Ecological niche-modeling and prioritization of conservation-area networks for Mexican herpetofauna. Conservation Biology, 24, 1031-1041.

Walther, G., Post, E., Convey, P., Menzel, A., Parmesan, C., Beebee, T.J.C., Fromentin, J., Hoegh-Guldberg, O. \& Bairlein, F. (2002) Ecological responses to recent climate change. Nature, 416, 389-395.

Williams, J.W. \& Jackson, S.T. (2007) Novel climates, no-analog communities, and ecological surprises. Frontiers in Ecology and Evolution, 5, 475-482.

Wisz, M.J., Hijmans, R.J., Li, J., Peterson, A.T., Graham, C.H., Guisan, A., \& The NCEAS Predicting Species Distributions Working Group. (2008) Effects of sample size on 
814 the performance of species distribution models. Diversity and Distributions, 14, 763-

815 773.

816 


\section{Tables}

818 Table 1. A description of the environmental data used in the four Maxent model types.

819 Values shown are percent contributions in each model, averaged across all runs under

820 current climate conditions. Maps of each variable across the study area are provided in

821 Appendix S2, and the response curves for each variable in the full model are provided in

822 Appendix S3.

\begin{tabular}{|c|c|c|c|c|}
\hline Variable & $\begin{array}{c}\text { Full } \\
\text { Model }\end{array}$ & $\begin{array}{c}\text { Reduced } \\
\text { Model }\end{array}$ & $\begin{array}{c}\text { Moderate } \\
\text { Correlation } \\
(r<0.7) \\
\end{array}$ & $\begin{array}{c}\text { Low } \\
\text { Correlatio } \\
\mathrm{n}(\mathrm{r}<0.5) \\
\end{array}$ \\
\hline Annual Mean Temperature & 4.2 & & 64.8 & 73.9 \\
\hline $\begin{array}{l}\text { Mean Diurnal Range in } \\
\text { Temperature }\end{array}$ & 2.1 & & 3.4 & \\
\hline Isothermality & 1 & & & \\
\hline Temperature Seasonality & 7.3 & 11 & & \\
\hline $\begin{array}{l}\text { Max Temperature of Warmest } \\
\text { Month }\end{array}$ & 1.6 & & 2.1 & \\
\hline $\begin{array}{l}\text { Min Temperature of Coldest } \\
\text { Month }\end{array}$ & 0.3 & & & \\
\hline Temperature Annual Range & 0.9 & & & \\
\hline $\begin{array}{l}\text { Mean Temperature of Wettest } \\
\text { Quarter }\end{array}$ & 2 & & 9 & 11.9 \\
\hline $\begin{array}{l}\text { Mean Temperature of Driest } \\
\text { Quarter }\end{array}$ & 0.8 & & 2.3 & \\
\hline $\begin{array}{l}\text { Mean Temperature of Warmest } \\
\text { Quarter }\end{array}$ & 0.2 & & & \\
\hline $\begin{array}{l}\text { Mean Temperature of Coldest } \\
\text { Quarter }\end{array}$ & 26 & 34.1 & & \\
\hline Annual Precipitation & 1.1 & & 3.2 & \\
\hline Precipitation of Wettest Month & 1.8 & & & \\
\hline Precipitation of Driest Month & 6.7 & 6.8 & & \\
\hline Precipitation Seasonality & 2.3 & & & \\
\hline Precipitation of Wettest Quarter & 3.1 & & & 3.4 \\
\hline Precipitation of Driest Quarter & 1.5 & & 5.4 & \\
\hline Precipitation of Warmest Quarter & 27.8 & 39.6 & & \\
\hline Precipitation of Coldest Quarter & 2.3 & & & \\
\hline Soil Type & 6.9 & 8.6 & 9.9 & 10.8 \\
\hline
\end{tabular}


823 Table 2. Results of model analysis (max SSS threshold, mean area under the curve, and true 824 skill statistic) for each model type.

\begin{tabular}{|lccc|}
\hline Model Type & Threshold & Average Test AUC & TSS \\
\hline Full Model & 0.3378 & $0.8280+/-0.0509$ & 0.6314 \\
Reduced Model & 0.3293 & $0.8283+/-0.0470$ & 0.5831 \\
$\begin{array}{l}\text { Moderate Correlation } \\
(\mathrm{r}<0.7)\end{array}$ & 0.3079 & $0.8214+/-0.0487$ & 0.5733 \\
Low Correlation $(\mathrm{r}<0.5)$ & 0.2662 & $0.8148+/-0.0494$ & 0.5398 \\
\hline
\end{tabular}

825

826

827

828

829

830

831

832

833

834

835

836

837

838

839

840

841

842

843

844

845

846

847 


\section{$848 \quad$ Figures}

849
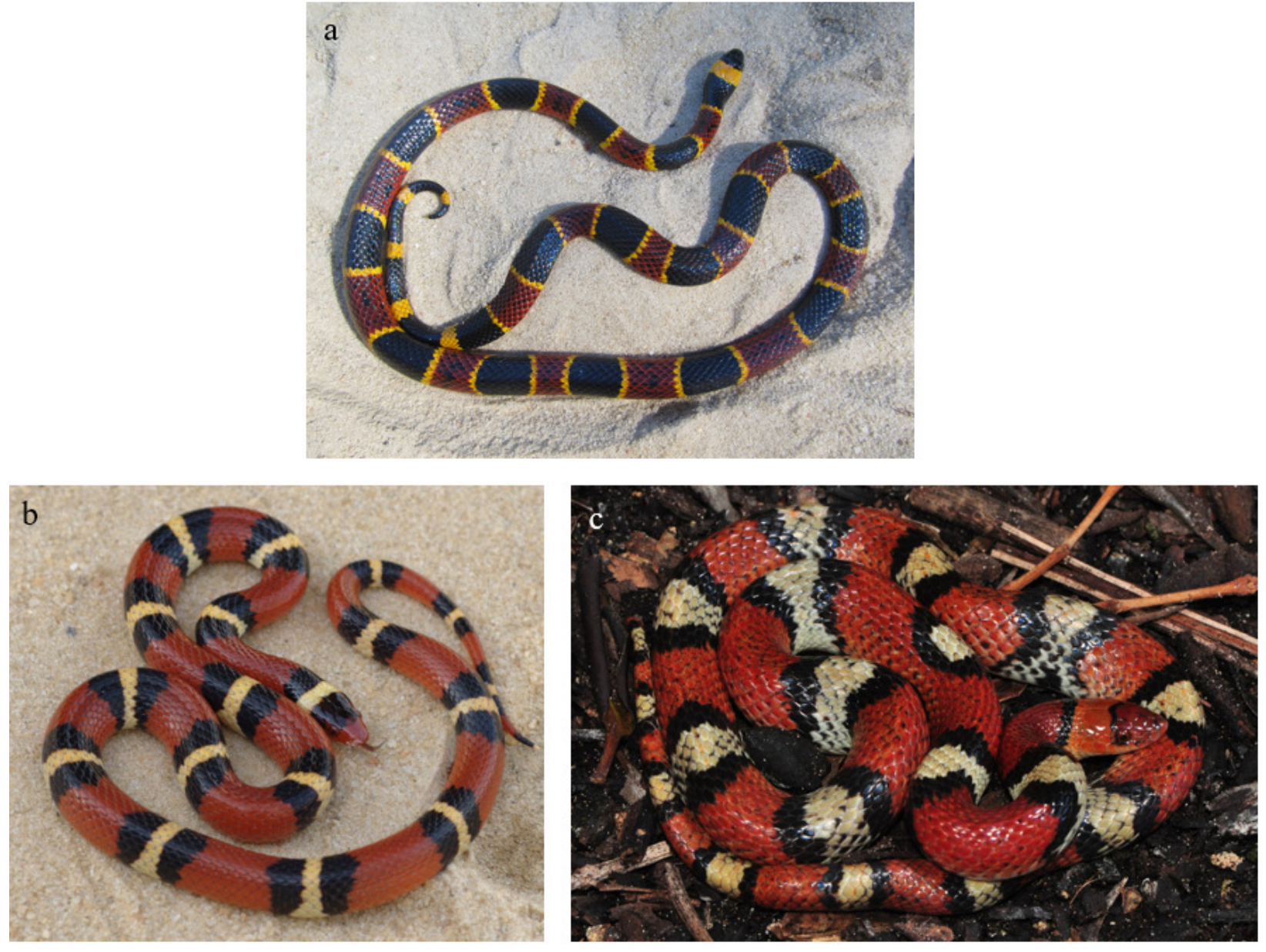

850

851 Figure 1. Pictures of (a) the venomous coral snake (Micrurus fulvius) (photo credit:

852 Christopher Akcali) and its non-venomous mimics, (b) the scarlet king snake (Lampropeltis

853 elapsoides) (photo credit: David Kikuchi) and (c) the scarlet snake (Cemophora coccinea) 854 (photo credit: Troy Hibbits). 

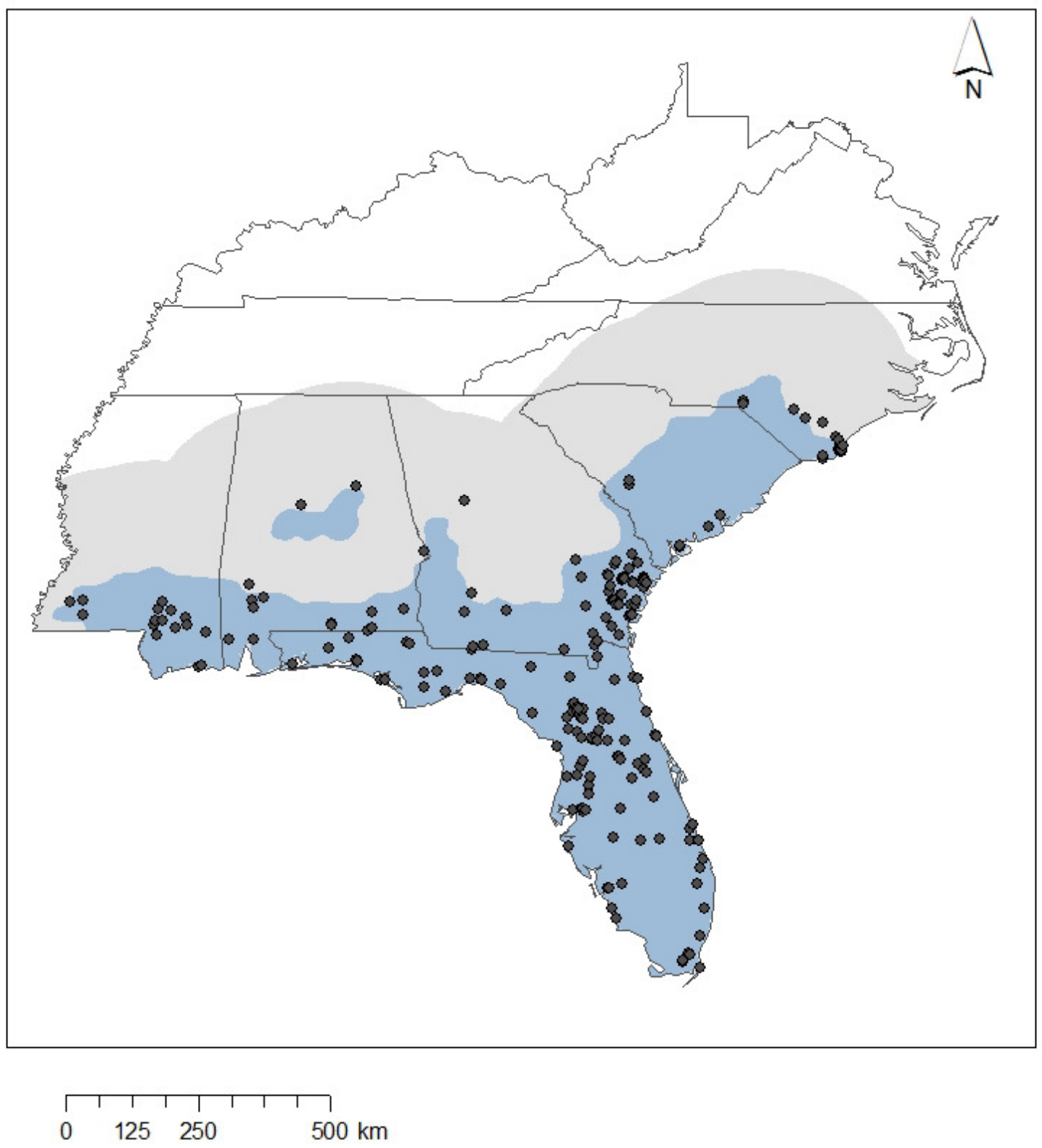

\section{IUCN Range}

200 km Dispersal Buffer

- Locality Points

857 Figure 2. Study area. Blue represents range of the eastern coral snake according to the 858 International Union for the Conservation of Nature, while gray indicates the full area of 859 study used in this research when accounting for a 200-km dispersal buffer. Points shown 860 are occurrence records $(n=142)$ used to create all models. Note that ten points did not 861 overlap with bioclim data and therefore were not used in models. 
A. Full Model

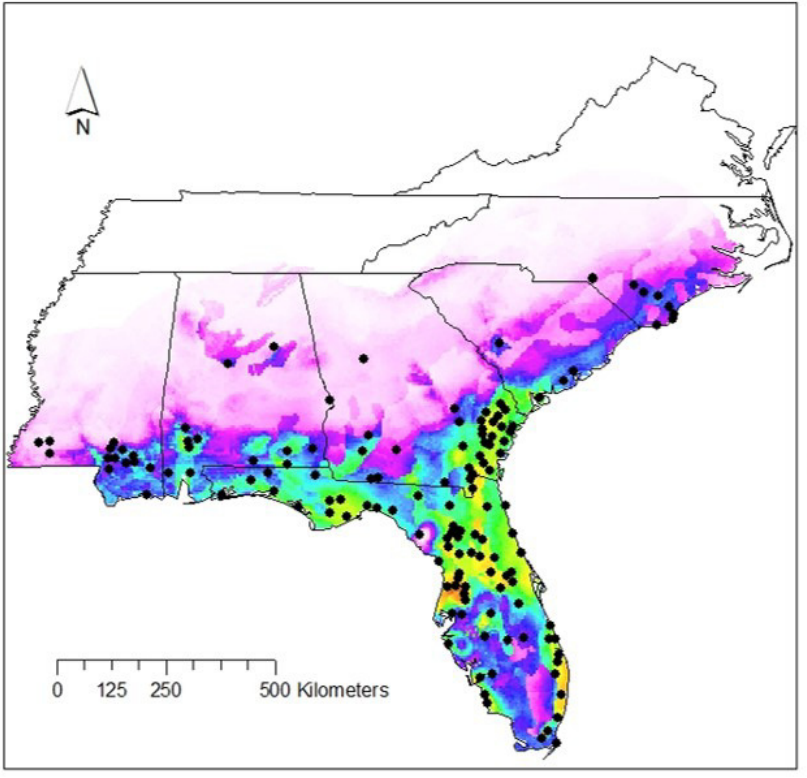

C. Moderate Correlation Model $\mathrm{r}<0.7$

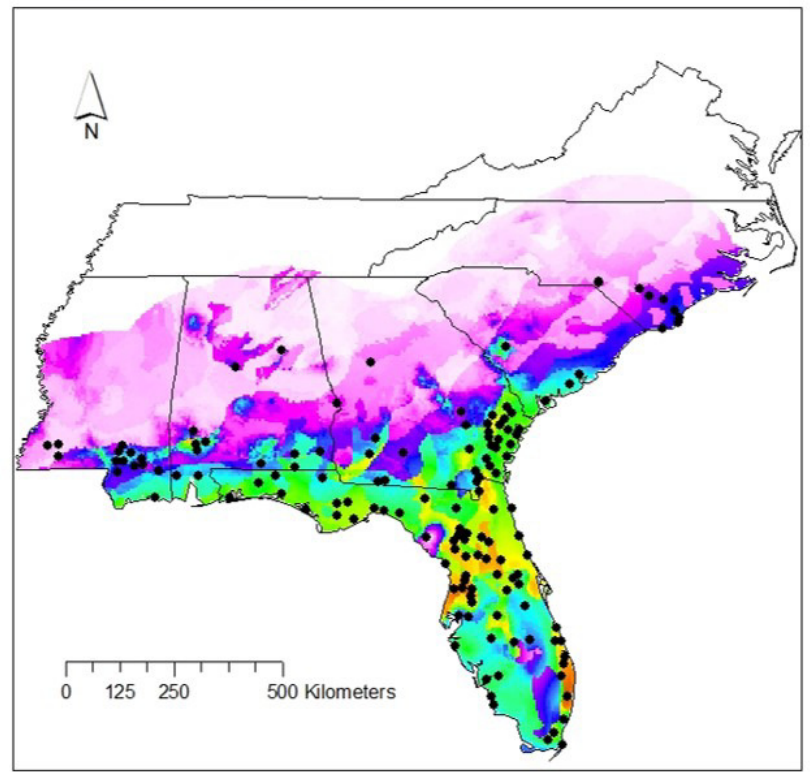

Habitat Suitability

- High : 1

Locality points $1950-2000$
B. Reduced Model

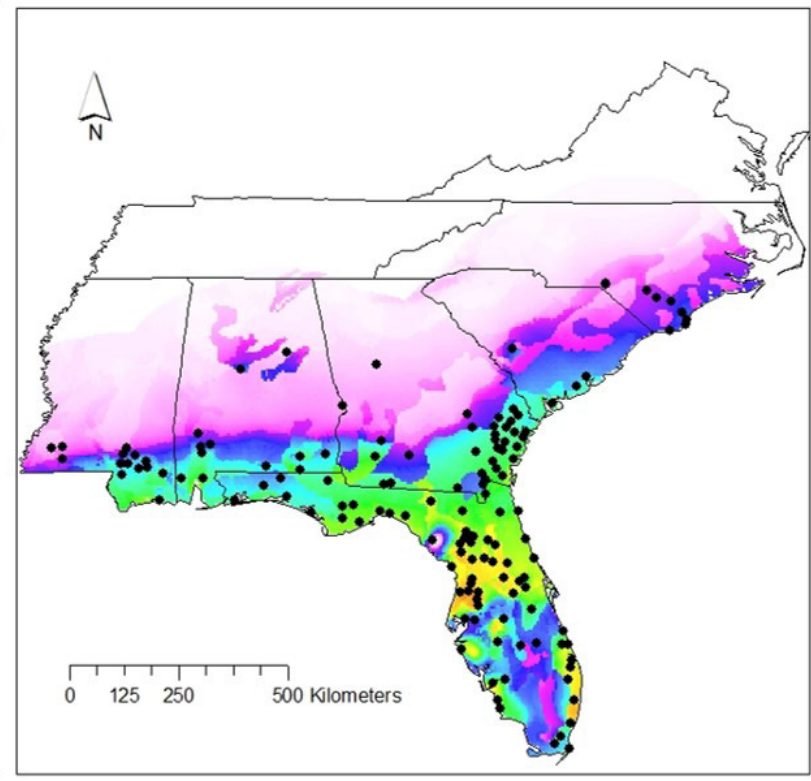

D. Low Correlation Model $\mathrm{r}<0.5$

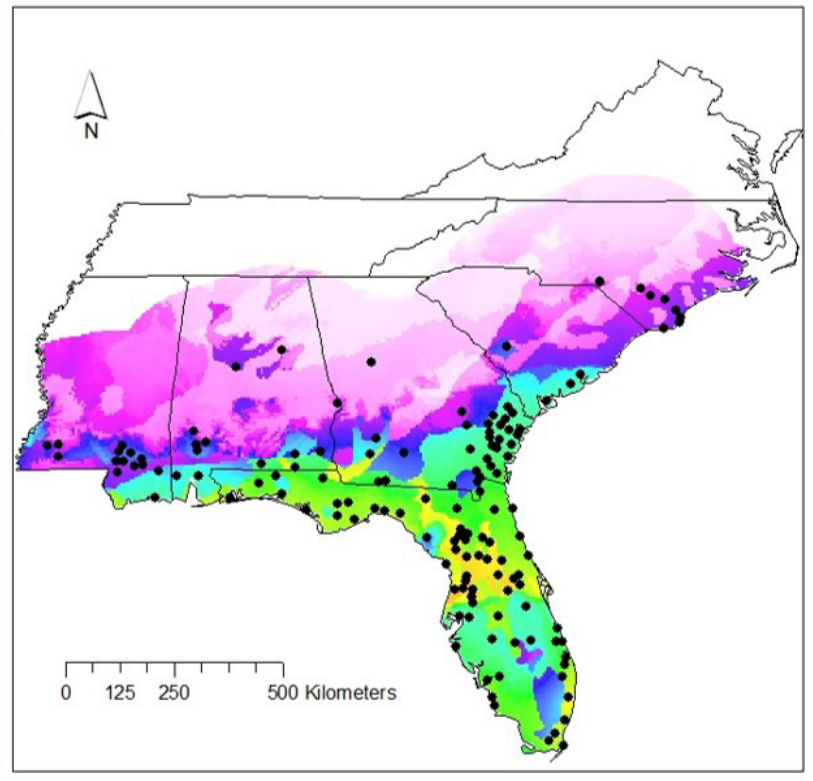


863 Figure 3. Habitat suitability for M. fulvius throughout the Southeast under current climate

864 conditions, 1950-2000. a. Full model, b. Reduced model, c. Moderate Correlation model, d.

865 Low Correlation model. 
A. GISS-E2 R Full Model

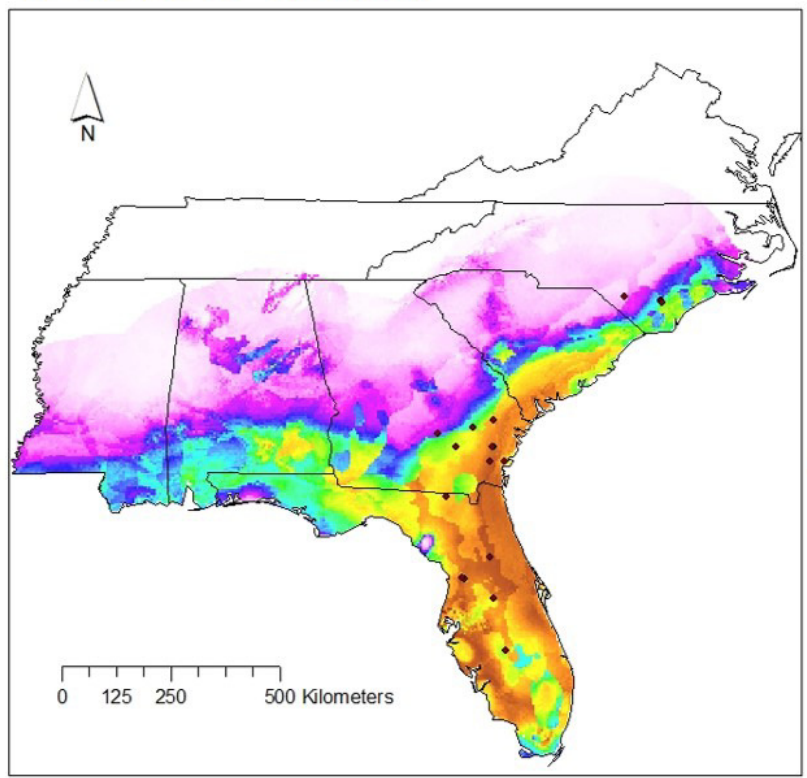

C. MIROC-ESM Full Model

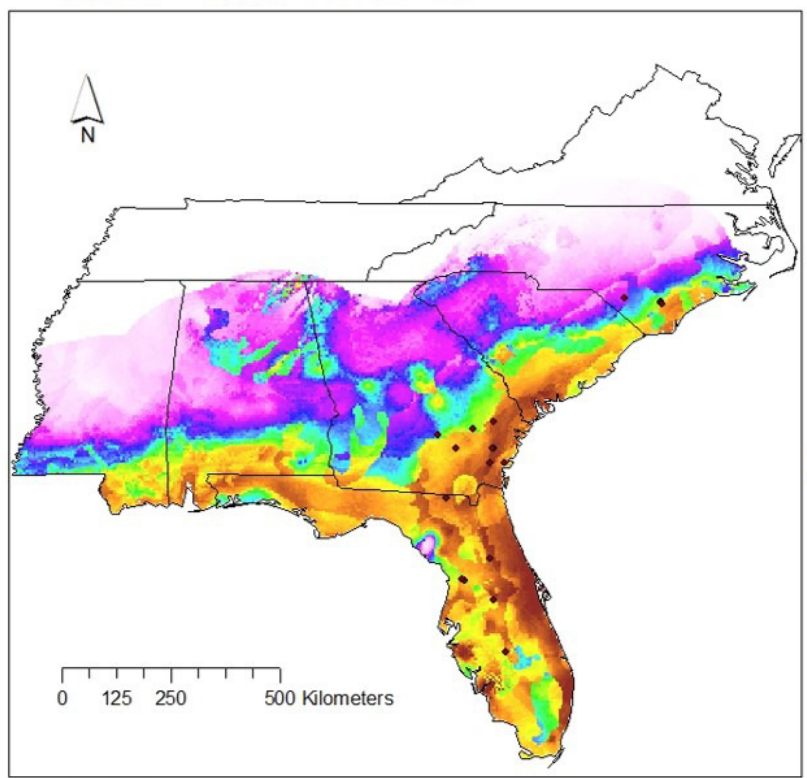

\section{Habitat Suitability}

High : 1
- Low : 0

\section{Locality points $2001-2015$}

B. GISS-E2 R Reduced Model

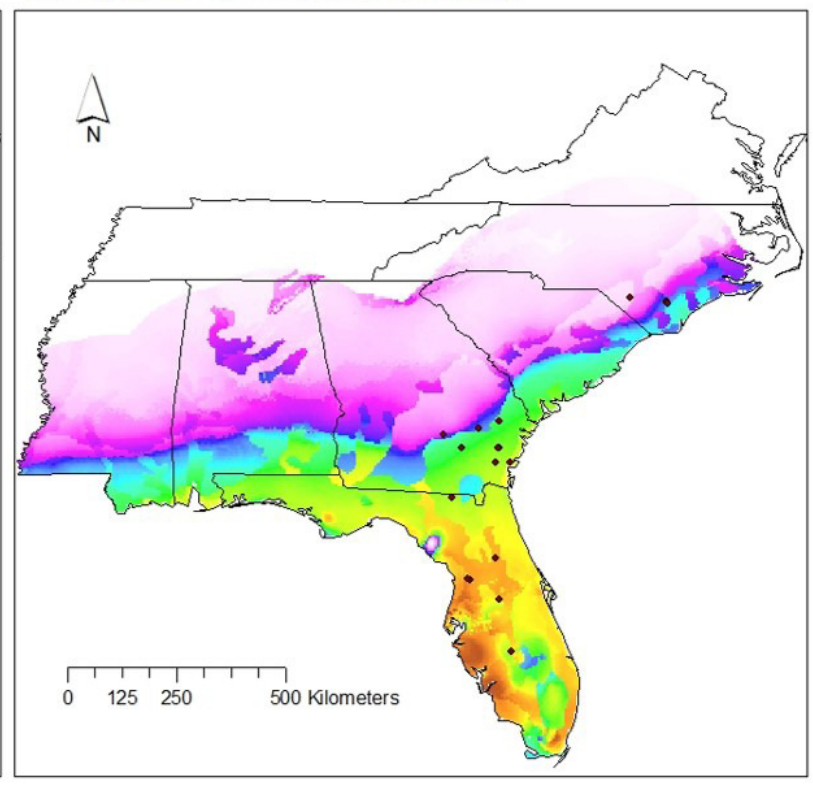

D. MIROC-ESM Reduced Model

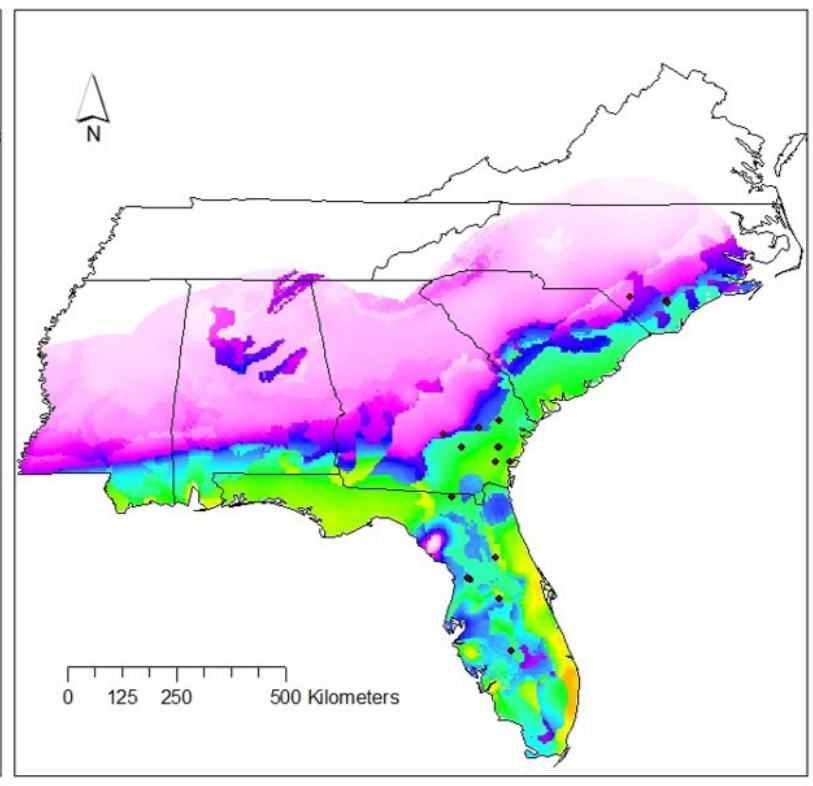

866

867

868

869

Figure 4. Habitat suitability for M. fulvius in the near future (2050) throughout the Southeast according to GISS-E2-R (NINT) (a. Full model, b. Reduced model) and MIROCESM (c. Full model, d. Reduced model). 

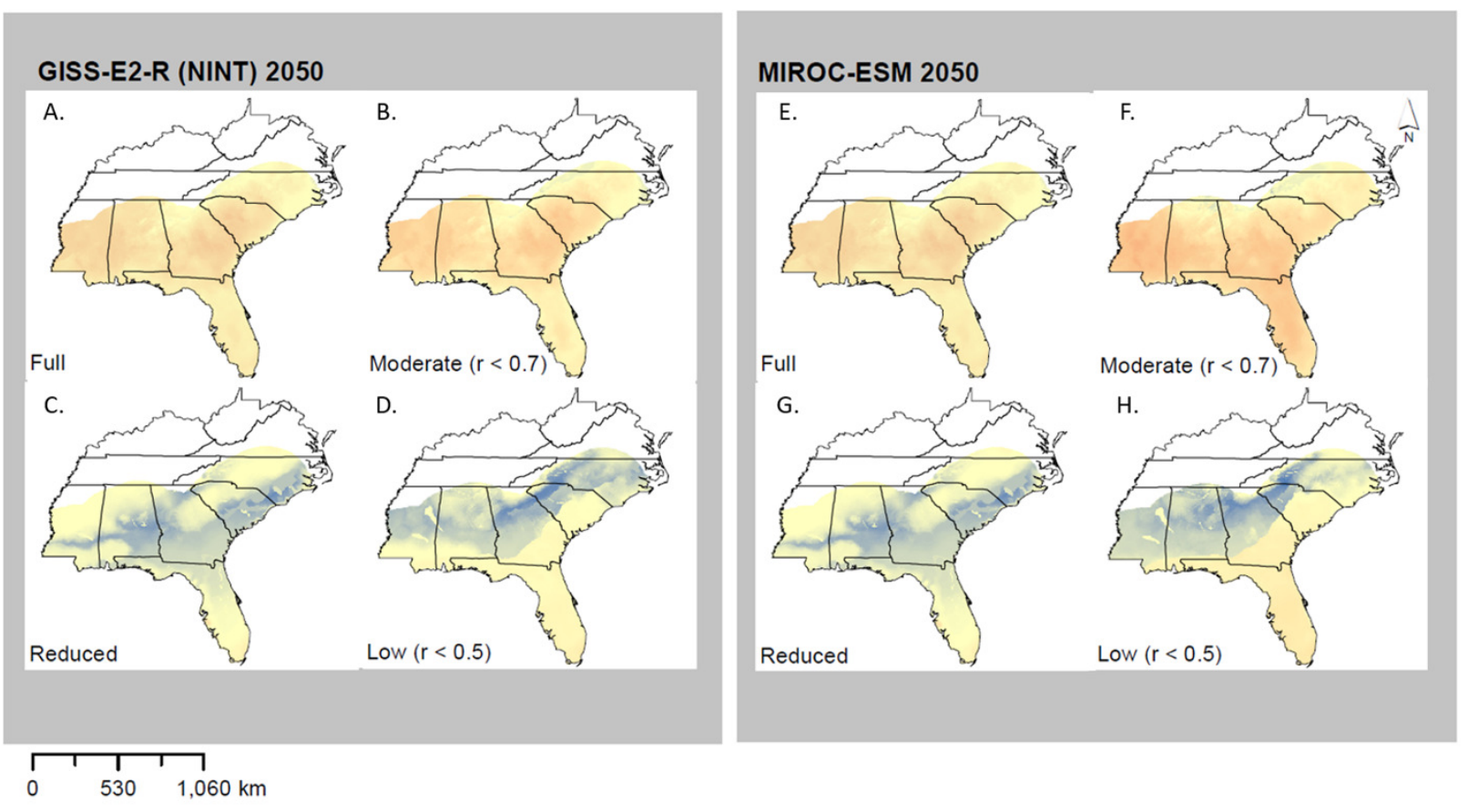

\section{Climate Similarity}

870

$$
\text { High : } 100
$$

871 Figure 5. Multivariate environmental similarity surfaces (MESS) analysis for both GISS-E2-

872 R (NINT) (a. Full model, b. Moderate correlation, c. Reduced model, and d. Low correlation)

873 and MIROC-ESM (e. Full model, f. Moderate Correlation, g. Reduced Correlation, and h. Low

874 Correlation) models. MESS analysis measures climate similarity to training range when

875 projecting a model. Negative values indicate a low similarity and therefore high climate

876 novelty, while positive values indicate a high similarity and therefore low novelty. 
A. GISS-E2 R Full Model

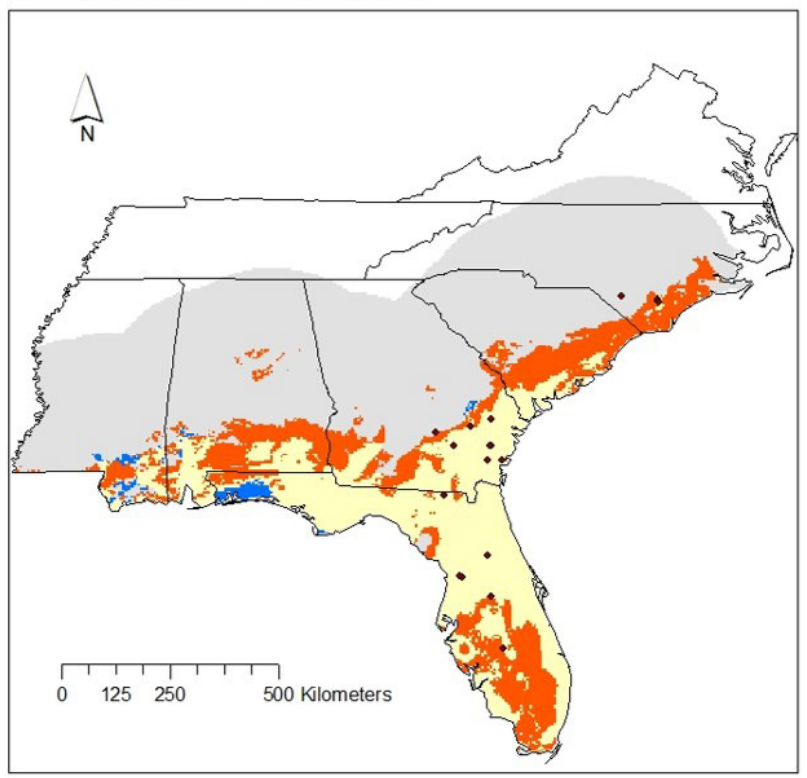

C. MIROC-ESM Full Model

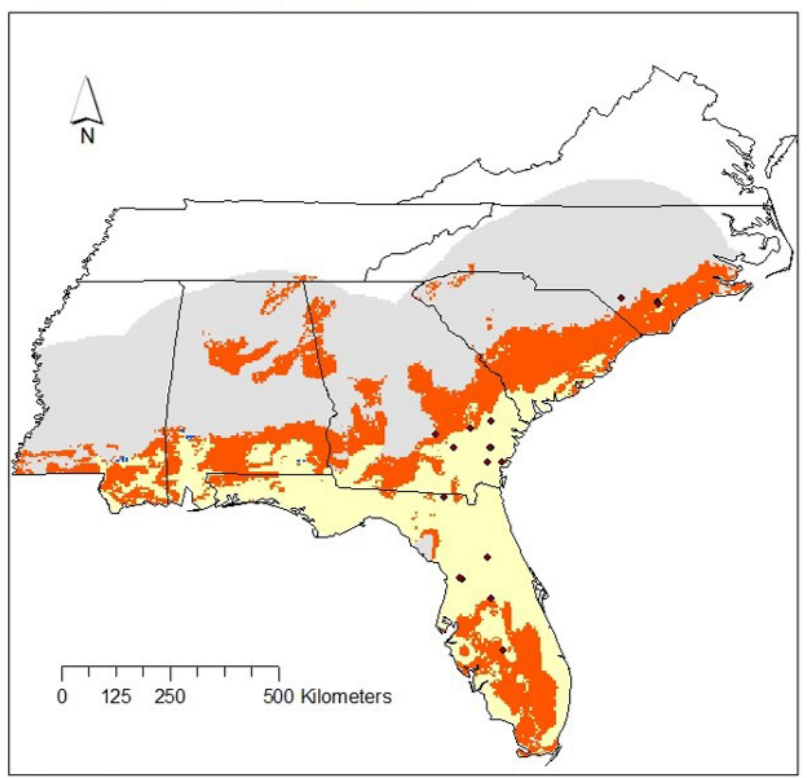

\section{Change in Habitat Suitability}

\begin{tabular}{|l}
\hline Predicted Range Expansion \\
Predicted Range Retraction \\
$\square$ Unsuitable Habitat \\
$\square$ Suitable Habitat
\end{tabular}

B. GISS-E2 R Reduced Model

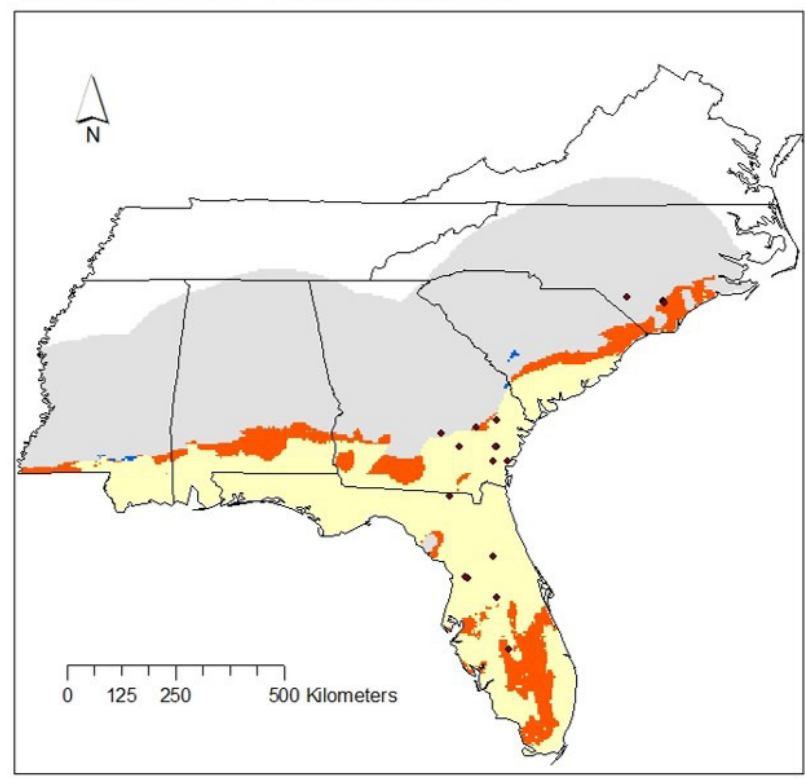

D. MIROC-ESM Reduced Model

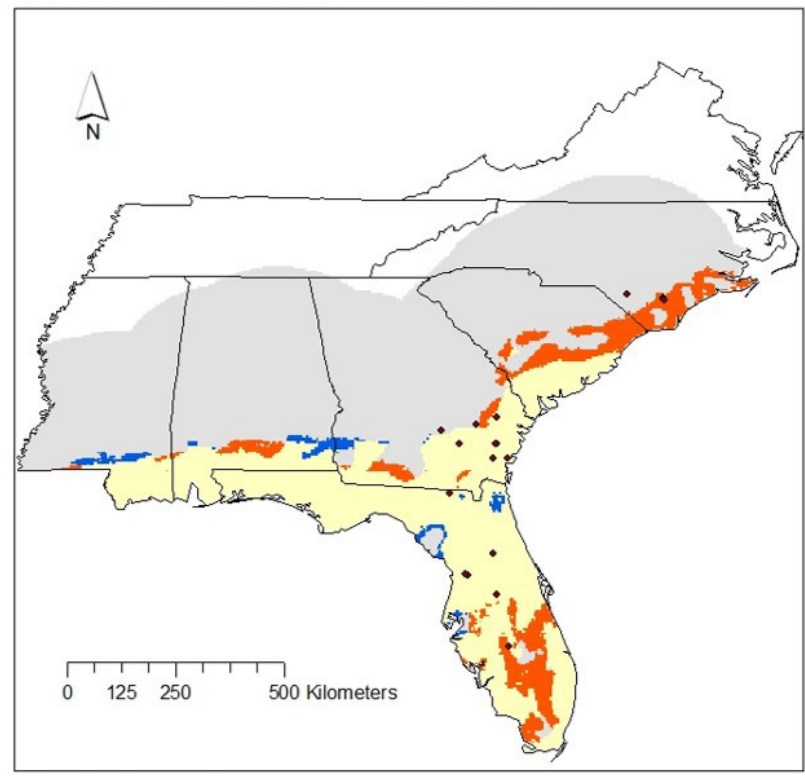

Locality points $2001-2015$

Figure 6. Change in suitable habitat from current conditions (1950-2000) to near future 880 conditions (2050) according to results of GISS-E2-R (NINT) (a. Full model, b. Reduced model) and MIROC-ESM (c. Full model, d. Reduced model) scenarios. 